\title{
Audiology and \\ Neurotology
}

\section{Sympathetic Nervous System Regulation of Auditory Function}

\author{
Chaoyong Tian Dingjun Zha \\ Department of Otolaryngology Head and Neck Surgery, Xijing Hospital, Fourth Military Medical University, Xi'an, China
}

\section{Keywords}

Adrenaline $\cdot$ Autonomic nervous system $\cdot$ Cochlea $\cdot$ Hearing disorders · Noradrenaline

\begin{abstract}
Background: The auditory system processes how we hear and understand sounds within the environment. It comprises both peripheral and central structures. Sympathetic nervous system projections are present throughout the auditory system. The function of sympathetic fibers in the cochlea has not been studied extensively due to the limited number of direct projections in the auditory system. Nevertheless, research on adrenergic and noradrenergic regulation of the cochlea and central auditory system is growing. With the rapid development of neuroscience, auditory central regulation is an extant topic of focus in research on hearing. Summary: As such, understanding sympathetic nervous system regulation of auditory function is a growing topic of interest. Herein, we review the distribution and putative physiological and pathological roles of sympathetic nervous system projections in hearing. Key Messages: In the peripheral auditory system, the sympathetic nervous system regulates cochlear blood flow, modulates cochlear efferent fibers, affects hair cells, and influences the habenula region. In central auditory pathways, norepinephrine is essential for
\end{abstract}

plasticity in the auditory cortex and affects auditory cortex activity. In pathological states, the sympathetic nervous system is associated with many hearing disorders. The mechanisms and pathways of sympathetic nervous system modulation of auditory function is still valuable for us to research and discuss.

(c) 2021 S. Karger AG, Basel

\section{Introduction}

Sympathetic efferent pathways form a component of the autonomic nervous system. Sympathetic nerve postganglionic fiber neurotransmitters predominantly comprise norepinephrine (NE), adrenaline, acetylcholine, purine, and polypeptides. Adrenergic receptors (ARs) regulate the functional effects of $\mathrm{NE}$ and adrenaline. Three types of ARs exist: $\alpha 1, \alpha 2$, and $\beta$. These ARs belong to the $G$ protein-coupled receptor superfamily. Each AR comprises 3 subtypes: $\alpha 1 \mathrm{a}, \alpha 1 \mathrm{~b}$, and $\alpha 1 \mathrm{~d} ; \alpha 2 \mathrm{a}, \alpha 2 \mathrm{~b}$, and $\alpha 2 \mathrm{c}$; and $\beta 1, \beta 2$, and $\beta 3$. The ARs are widely present across the peripheral and central auditory pathways (shown in Table 1) [Sutin and Minneman, 1985; Boyajian et al., 1987; Wanaka et al., 1989; Carrasco et al., 1990; Gjedde et al., 1991; Martin et al., 1994; Ebert, 1996; Day et al., 1997; Domyancic and Morilak, 1997; de Minteguiaga et al., 


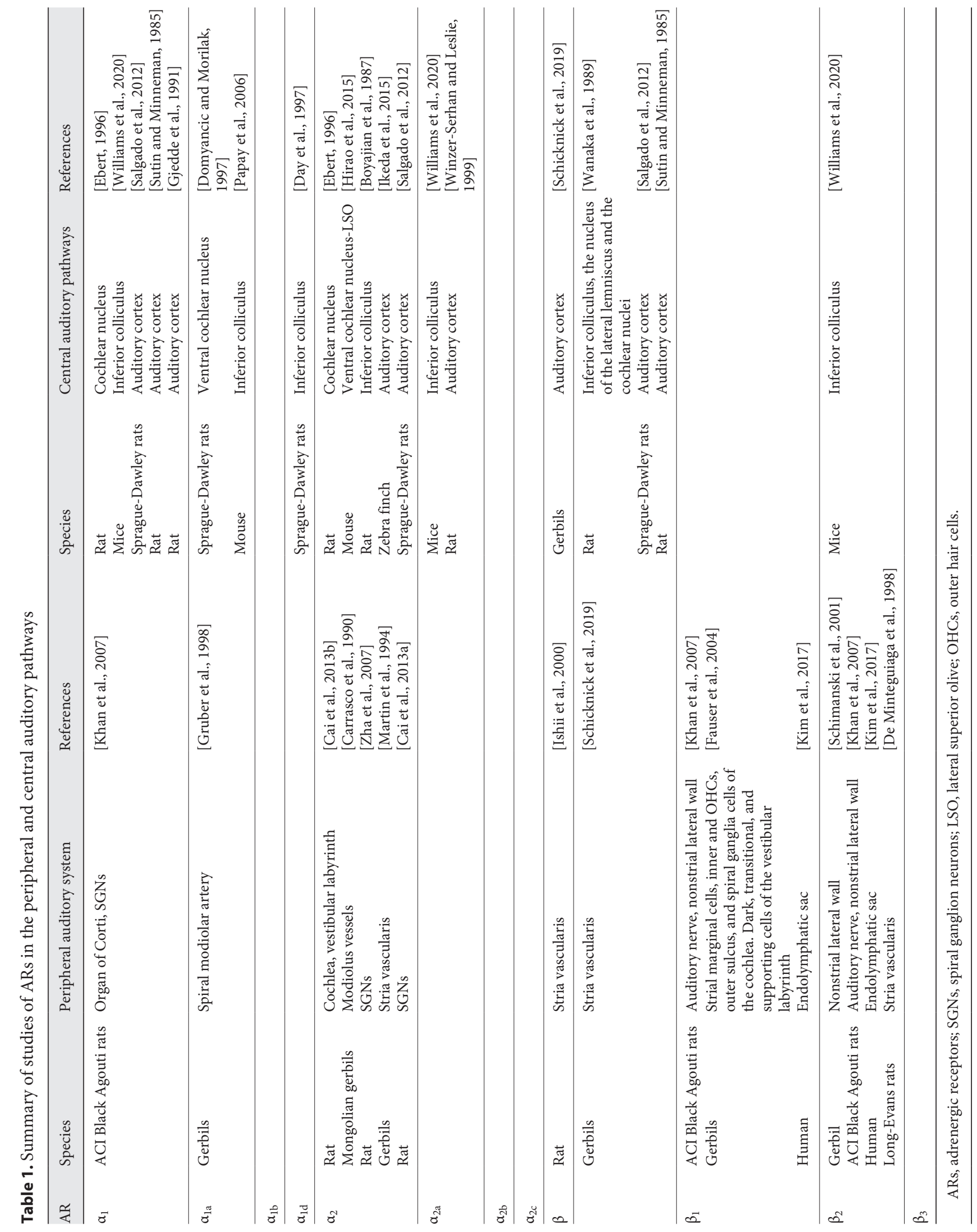




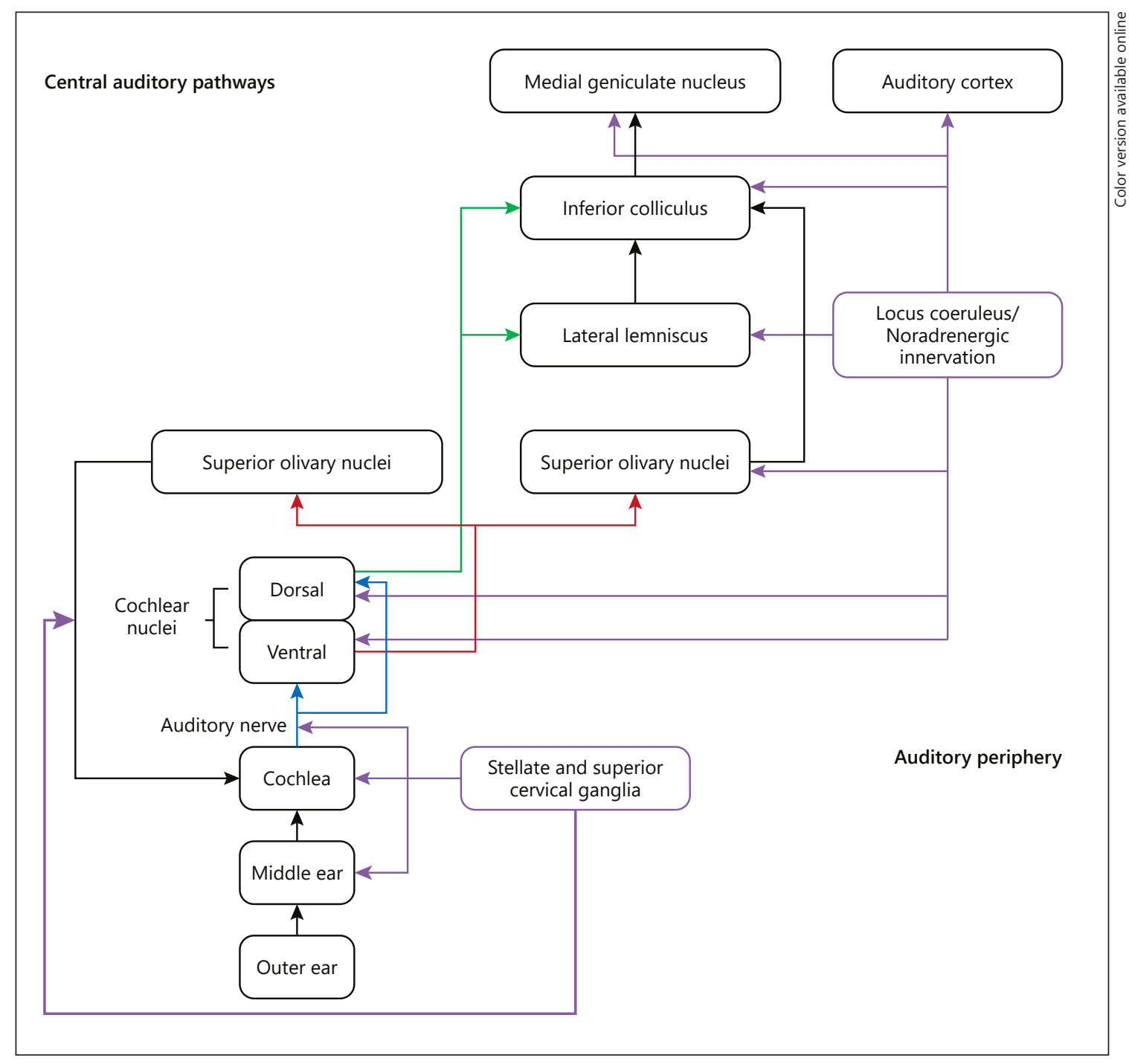

Fig. 1. Schematic of sympathetic nervous system modulation of hearing. Afferent auditory pathway projections are indicated by black, blue, red, and green arrows. Olivo-cochlear bundle is indicated by a gray arrow. Putative projections or regulation by the sympathetic nervous system are indicated by purple arrows.

1998; Gruber et al., 1998; Winzer-Serhan and Leslie, 1999; Ishii et al., 2000; Schimanski et al., 2001; Fauser et al., 2004; Papay et al., 2006; Khan et al., 2007; Zha et al., 2007; Salgado et al., 2012; Cai et al., 2013a, b; Hirao et al., 2015; Ikeda et al., 2015; Kim et al., 2017; Schicknick et al., 2019; Williams et al., 2020] and are positioned to affect auditory and vestibular processing.

The regulation of peripheral and central auditory pathways by the sympathetic nervous system has been reported [Foote et al., 1975; Chikamori et al., 1980; Kossl and Vater, 1989; Laurikainen et al., 1993; Ren et al., 1993a, b; Manunta and Edeline, 1997, 1999, 2004; Edeline et al., 2011; Martins and Froemke, 2015]. In the periphery, sympathetic nerves mainly regulate cochlear blood flow (CBF) [Spoendlin and Lichtensteiger, 1966; Spoendlin, 1981; Laurikainen et al., 1993; Ren et al., 1993a, b]. Centrally, the key roles of locus coeruleus (LC)-NE on auditory pathways are predominantly inhibitory [Foote et al., 1975; Chikamori et al., 1980; Kossl and Vater, 1989; Manunta and Edeline, 1997, 1999]. In pathological states, dysfunction of the sympathetic nervous system may lead to auditory disorders. Modulation of the auditory system by the sympathetic nervous system is complex. Understanding this relationship is of high clinical significance. For example, a mechanism was reported that demonstrated a vessel associated with sympathetic led to cochle- 
ar vasoconstriction and exacerbated noise-induced cochlear damage [Hildesheimer et al., 1991].

In this review, we highlight the key roles of the sympathetic nervous system in auditory function. First, we focus on the relationship between sympathetic activity and peripheral auditory processes, followed by an evaluation of the relationship between sympathetic activity and central auditory pathways. Finally, we summarize research on sympathetic nervous system modulation of auditory disorders. This review provides timely insight into the mechanisms underpinning sympathetically related auditory dysfunction to guide future research in this area.

\section{Sympathetic Activity and Peripheral Auditory System}

The peripheral auditory system (shown in Fig. 1) consists of the external ear, middle ear, inner ear, and auditory nerve. In mammals, the peripheral auditory system receives extensive adrenergic innervation from the sympathetic nervous system, particularly from the superior cervical ganglia (SCG) and stellate ganglion (SG). Tyrosine-hydroxylase-immunoreactive nerve fibers are expressed in most regions of the middle ear mucosa, and these fibers are close to small-caliber vessels [Uddman et al., 1983; Nagaraj and Linthicum, 1998]. The sympathetic nervous system projecting into the inner ear comprises 2 main components [Spoendlin and Lichtensteiger, 1967; Spoendlin, 1981; Hozawa and Kimura, 1990]: a vesselassociated component originating from the SG bilaterally and a dense plexus forming around the major arteries, and a vessel-independent component originating ipsilaterally from the SCG producing multiple terminals in the osseous spiral lamina region, which contains the cell bodies and axons of cochlear nerve fibers [Spoendlin and Lichtensteiger, 1966; Borg et al., 1974; Densert and Flock, 1974]. The functional significance of cochlear adrenergic innervation includes its roles in the regulation of blood flow volume, and in the control the metabolism of inner hair cells (IHCs), and outer hair cells, as well as efferent and afferent axons [Densert, 1974].

The blood supply to the cochlea originates from the common cochlear artery, which includes the spiral modiolar and vestibulocochlear arteries. The regulation of CBF by the sympathetic nervous system and ARs is well established. Sympathetic innervation influences vascular tone. By regulating arteriole diameter, the vessel-associated component has a significant effect on CBF [Brechtelsbauer et al., 1990; Laurikainen et al., 1993, 1997; Ren et al., 1993b]. Disruption of the sympathetic nervous system partially abolished, found that sympathetic activation contributes to sound-induced reduction of CBF [Burwood et al., 2020]. Unilateral and bilateral SG blockade resulted in effects of differing magnitude on CBF on each side, although both resulted in an increase in CBF. In contrast, electrical stimulation of the SG reduced CBF [Laurikainen et al., 1993]. Stimulation of the SCG decreased ipsilateral CBF. However, superior cervical ganglionectomy did not have any significant effect on tonic CBF levels [Laurikainen et al., 1997]. ARs regulate the function of the cochlea and influence CBF [Ren et al., $1993 \mathrm{~b}]$. In the vascular system of the cochlea, $a 1-$ and $a 2-$ ARs are differentially distributed and are involved in CBF regulation; these differences are underpinned by interspecies variations [Carrasco et al., 1990; Ohlsen et al., 1991; Laurikainen et al., 1994; Gruber et al., 1998]. AR subtypes are differentially distributed in the cochlea. For instance, $\alpha 1$-ARs are expressed in the organ of Corti and spiral ganglion (regions unrelated to vasculature), $\beta 1$ ARs are expressed in nerve fibers beneath IHCs, and $\beta 2$ ARs are expressed in nerve fibers crossing the habenula perforate and project to IHCs [Khan et al., 2007]. Pharmacological approaches have been utilized to elucidate the functional neuroanatomy of $\alpha 2$-ARs in the mammalian cochlea, such as in modiolus vessels [Carrasco et al., 1990], spiral ganglion neurons (SGNs) [Zha et al., 2007], and stria vascularis [Martin et al., 1994]. Ishii et al. [2000] reported that cells constituting the stria vascularis may express $\beta$-ARs. Nonstrial lateral wall tissues express $\beta 1$ and $\beta 2$-ARs, but the $\beta 2$-AR is the predominant functional receptor subtype [Schimanski et al., 2001]. Khan et al. [2007] provided strong evidence that ARs are expressed in the SGNs and organ of Corti, highlighting a possible mechanism of regulation of peripheral auditory sensory function via adrenergic input [Khan et al., 2007]. Cai et al. [2013b] reported that $\alpha 2$-ARs were widely distributed in various areas and the cellular sites of $\alpha 2$-ARs vary between different cell subtypes, AR subtypes, and timepoints. After that, Cortada et al. [2017] reported that brimonidine, acting directly via $\alpha 2$-ARs, protects hair cells from gentamicin-induced toxicity. At the same time, a report by Inamoto et al. [2017] demonstrated that the isoproterenol (a $\beta$-AR agonist)-induced maximum change in endolymphatic hydrostatic pressure in the ampulla was significantly smaller than in the cochlea. However, another investigation provided functional evidence for the involvement of $\beta 1$-and $\beta 2$-ARs in apical electrogenic ion transport in human endolymphatic sac epithelium [Kim et al., 2017].
Tian/Zha 
Responses of the vessel-independent component close to the habenula perforated to noise and its role in cochlear homeostasis are unclear. Electrical stimulation of the sympathetic trunk with superior cervical ganglionectomy increased $\mathrm{N} 1$ wave amplitude of compound action potentials (CAPs) to $15-20 \%$. Increased variability in N1 wave amplitude after sympathetic stimulation has been reported [Pickles, 1979; Lee and Møller, 1985]. In animal experiments, changes in N1 wave amplitude produced different results. Compared to high SCG stimulus intensities, low SCG stimulus intensities caused a greater increase in latency of the N1 response [Lee and Møller, 1985]. The dynamic range of CAP was smaller after a unilateral cervical sympathectomy compared to that in nonsympathectomized cochleas [Hultcrantz et al., 1982]. In conclusion, these findings indicate a regulatory role of SCG fibers on afferent auditory nerve signals, although the magnitude of its effects remains uncertain. Perlman and Kimura [1955] reported that sympathetic stimulation did not affect blood flow of the stria vascularis. NE may affect the permeability of the spiral modiolar artery. However, this area contains extensive terminals, and modulation of permeability is unlikely to be the only physiological function of this extensive innervation. One factor that should be considered is that catecholamines may exert direct effects on outer and IHC metabolism. Zha et al. [2007] reported that NE input to SGNs may modulate auditory transmission by influencing GABA responses. Early physiological studies have shown that sympathetic fibers affect the latency and/or amplitude of the auditory nerve CAP N1 wave, highlighting sympathetic modulation of afferent nerve function, although consistent explanations of the underlying mechanism are lacking [Pickles, 1979; Muchnik et al., 1983; Lee and Møller, 1985]. Wangemann and Wonneberger [2005] reported that sympathetic innervation led to vasoconstriction of the main blood supply of the cochlea in guinea pigs and gerbils. Conversely, SG block improved the hearing parameters of normal CBF in rats [Firat et al., 2008]. The decrease in CBF was significantly greater following propofol infusion with topical epinephrine compared to that following control treatment, and the threshold was increased [Jang et al., 2016]. These findings highlight potential avenues for clinical investigation. Notably, the cochlear sympathetic system is associated with age and sex [Vicente-Torres and Gil-Loyzaga, 2002].

The cochlea receives 2 categories of efferent nerve fibers, including the lateral and medial olivocochlear efferent fibers. Lateral olivocochlear fibers contact type 1 auditory nerve dendrites below IHCs, and medial olivocochle-

Sympathetic Modulation of Auditory

Function ar fibers contact the outer hair cells. Alongside olivocochlear efferent fibers, the cochlea also receives sympathetic adrenergic efferent fibers. Morphological research suggests a sympathetic role in the habenula region, where afferent axons have lost their myelin sheaths. Just below the basilar membrane of the nerve bundles, adrenergic nerve terminals and prominent groups of terminals are regularly observed around the nerve bundles. This is the location where action potentials are meant to be generated. NE released in this area may affect the threshold for nerve impulse initiation [Densert, 1974]. Mulders and Robertson [2000] suggested a direct input to medial olivocochlear neurons from NE-containing neural pathways. They observed an excitatory action of NE on both medial and lateral olivocochlear neurons. These results indicate that noradrenergic inputs can regulate cochlear efferent functions [Mulders and Robertson, 2005]. Otherwise, adrenergic regulation of neural/supporting cell function within the organ of Corti is a novel identified mechanism that may influence afferent signaling [Khan et al., 2007]. Nevertheless, the modulatory mechanisms underpinning these processes remain unclear.

\section{Sympathetic Activity and Central Auditory Pathways}

The central auditory system (shown in Fig. 1) comprises the dorsal and ventral cochlear nucleus and superior olivary nuclei in the brainstem, lateral lemniscus and inferior colliculus in the midbrain, medial geniculate nuclei of the thalamus, and auditory cortex in the temporal lobe of the cerebral cortex.

In rodents and primates, the neurons that releases $\mathrm{NE}$ are located in the brainstem in clusters named $\mathrm{A} 1-\mathrm{A} 7$ [Dahlström and Fuxe, 1964]. Of these, the LC (A6) projects to most regions in the brain [Loughlin et al., 1986], except the basal ganglia [Berridge and Waterhouse, 2003], and is the only source of noradrenergic innervation of the cerebral cortex [Jones et al., 1977; Moore and Bloom, 1979]. Immunohistochemical analyses suggest that the majority of neurons in the LC are noradrenergic [Grzanna and Molliver, 1980].

Brainstem noradrenergic neurons comprise a small yet diverse population of cells that project to almost all regions of the central nervous system. In a mature system, these neurons are anatomically subdivided into 6 nuclei: A1, A2, A5, A7, LC, and subcoeruleus. LC plasticity induces changes in auditory cortex responses lasting on the scale of hours and improves auditory perception for days to weeks [Martins and Froemke, 2015]. The selective 
plasticity induced in the frequency tuning of auditory cortex neurons by LC stimulation is bidirectional [Edeline et al., 2011]. Noradrenergic innervation of the cochlear nucleus [Andén et al., 1966; Comis and Whitfield, 1968], superior olivary complex (SOC) [Wynne and Robertson, 1996; Woods and Azeredo, 1999; Mulders and Robertson, 2001], and inferior colliculus [Klepper and Herbert, 1991] has been reported and identified to originate in the LC. Mulders and Robertson [2005] reported that a significant component of the noradrenergic innervation of the guinea pig SOC arises in the locus subcoeruleus, and this structure could be the homolog of the LC in other species. The noradrenergic system also innervates neurons in the superior olive that project to the cochlear nucleus [Behrens et al., 2002]. Inhibitory effects were observed in cochlear nucleus neurons of bats and cats during NE iontophoresis [Chikamori et al., 1980; Kossl and Vater, 1989]. The SOC in the rat brainstem comprises many sub-nuclei, including the medial superior olive, lateral superior olive, medial nucleus of the trapezoid body, ventral nucleus of the trapezoid body, and various other less well-defined peri-olivary areas [Harrison and Feldman, 1970; Osen et al., 1984]. It comprises a component of the ascending auditory pathway that receives input from the cochlear nuclei and projects to higher central auditory centers in the brain [Beyerl, 1978; Coleman and Clerici, 1987; Friauf and Ostwald, 1988; Thompson and Thompson, 1993; Kelly et al., 1998; Oliver, 2000]. The lateral superior olive is a brainstem node that receives noradrenergic projections from the LC and is a site where acoustic information is first computed [Woods and Azeredo, 1999; Mulders and Robertson, 2001].

The lateral lemniscus contains dorsal, ventral, and intermediate nuclei. Noradrenergic innervation of the nucleus arises exclusively from an ipsilateral group of neurons scattered among the fibers of the lateral lemniscus. Noradrenergic neurons projecting to the LC and lateral lemniscus area were stimulated $40 \mathrm{~ms}$ before delivery of a tactile stimulus to the face, resulting in complete suppression [McBride and Sutin, 1984]. In the A7 LC cell group, numerous dopamine-beta-hydroxylase (DBH) positive neurons were noted within and medial to the lateral lemniscus [Mulders and Robertson, 2001]. However, the function of noradrenergic neurons projecting to these regions is not fully known.

Phenylethanolamine N-methyltransferase is an enzyme that converts NE into adrenaline. In monkeys, distribution of adrenergic innervation of the thalamus indicated a low to moderate density of phenylethanolamine
$\mathrm{N}$-methyltransferase fibers in the medial geniculate nucleus [Rico and Cavada, 1998]. The auditory role of adrenergic innervation and regulation of the medial geniculate nucleus is unknown.

The auditory cortex located in the temporal lobe of the cerebral cortex in monkeys and humans. NE is an important modulator of neuronal activity in the auditory cortex. The effect of LC-NE on central auditory pathways is typically inhibitory. Seminal research [Foote et al., 1975] reported that dose-dependent inhibitory effects of spontaneous and evoked activity were observed following NE application. Inhibitory effects were observed in 35-50\% of auditory cortex neurons in rats [Manunta and Edeline, 1997, 1999].

Pairing of auditory stimuli-induced LC plasticity leading to changes in auditory cortex responses and improvements in auditory perception. Selective alterations of a particular sound frequency-induced differential LC plasticity between the cortex and thalamus [Edeline et al., 2011; Martins and Froemke, 2015]. Brief increases in NE concentration-induced selective modifications in the turning curves of cortical neurons. In most situations, the effects are contrary to acetylcholine induction [Manunta and Edeline, 2004]. LC plasticity and NE application may involve different pathways/mechanisms to influence auditory cortex activity. The involvement of NE in critical period modulation remains obscure at present, although recent research has implicated NE in experience-dependent plasticity in the adult auditory cortex [Edeline et al., 2011]. Salgado et al. [2011] reported that NE influences cortical suppression in a layer-specific manner by reducing apical but increasing basal suppression onto layer II/ III pyramidal neuron dendrites. In songbirds, NE increases signal detection and information encoding of complex auditory stimuli by inhibitory spontaneous "noise" activity, and these actions are independent of local neuroestrogen synthesis [Ikeda et al., 2015]. NE has a key role in the primary auditory cortex and attention of stressed rats during tone discrimination [Pérez-Valenzuela et al., 2016]. Studies using DBH knockout (Dbh-/-) mice and controls in a biased acoustic environment during the auditory cortical critical period revealed that the best frequencies were redistributed in controls but not Dbh-/- mice. This suggests that NE is not critical for cortical circuit formation but is essential for plasticity in the auditory cortex during the critical period, demonstrating that NE is necessary for input-dependent plasticity in the developmental auditory pathway [Shepard et al., 2015].

Three AR families are expressed in the brain ( $\alpha 1, \alpha 2$, and $\beta 1-\beta 3$ ), which have specific presynaptic and postsyn-
98

Audiol Neurotol 2022;27:93-103 DOI: $10.1159 / 000517452$
Tian/Zha 
aptic sites and laminar expression patterns throughout the cortex [Berridge and Waterhouse, 2003]. Schicknick et al. [2019] reported that $\beta$-adrenergic signaling in the auditory cortex has task-related importance for discrimination learning of complex sounds. To explore the effect of basolateral amygdala $\beta 1$-ARs in fear responses, (arachidonylcyclopropylamide, a selective $\mathrm{CB} 1$ cannabinoid receptor agonist) was used to modulate $\mathrm{CB} 1 \mathrm{Rs}$. Receptor inactivation resulted in a bidirectional effect on arachidonylcyclopropylamide responses in contextual and acoustic fear conditioning [Nasehi et al., 2018].

\section{Regulation of Sympathetic Nervous System in Hearing Disorders}

Autonomic innervation of the inner ear is a research area of increasing interest as many hearing disorders, including tinnitus, vertigo, and sudden deafness may be caused by an autonomic disorder [Seymour and Tappin, 1951; Passe, 1953]. Cochlear ischemia has been associated with many hearing disorders, such as noise-induced hearing loss, age-related hearing loss, sudden sensorineural hearing loss, tinnitus, and Ménière's disease [Perlman et al., 1959; Thalmann et al., 1972; Santi and Duvall, 1978; Ren et al., 1995; Lamm and Arnold, 1996; Nuttall, 1999; Mom et al., 2001; Shi, 2011]. Based on the correlation about sympathetic activity and auditory pathways that we stated above, more and more studies focus on the clinical effects of the sympathetic nervous system in hearing disorders.

\section{Tinnitus}

Autonomic nervous system imbalance, which often occurs in patients with tinnitus-triggered stress. One candidate mechanism of tinnitus is hyperarousal caused by enhanced activation of the sympathetic nervous system. A blockade of the superior cervical sympathetic ganglion may be a useful alternative for patients with tinnitus not responding to conventional therapy [Koning et al., 2016]. Noninvasive vagus nerve stimulation reduces sympathetic preponderance in patients with tinnitus [Ylikoski et al., 2017]. Patients with chronic tinnitus received xenon phototherapy of the SG have a significant effect [Shimizu et al., 2018].

\section{Vertigo}

Vestibular disturbances associated with the autonomic nervous system [Yates, 1992; Biaggioni et al., 1998; Yates and Kerman, 1998; Yates et al., 2000, 2002; Ray and
Monahan, 2002; Ray and Carter, 2003]. SG block is recommended as a treatment of Ménière's disease [Warrick, 1969]. Sympathetic activity was increased by vertigo attacks in the patients with Ménière's disease [Kawasaki, 1993]. Currently, the sympathetic nervous system in vestibular pathology like Ménière's disease and all vestibular causes of vertigo are studied in humans. Activation of the sympathetic nervous system may adversely affect Eustachian tube function [Franz and Anderson, 2007]. A significantly asymmetric sympathetic hypofunction in the area of the postauricular region of the involved ear in Ménière's disease patients [Yildiz et al., 2007]. SG block can be beneficial in controlling Ménière's disease symptoms, highlighting the influence of the autonomic nervous system. Kim et al. [2017] reported that adrenergic stimulation regulated inner ear fluid ion homeostasis and impairment of this response by $\beta 1$-and $\beta 2$-ARs in the human endolymphatic sac could be a pathological mechanism underpinning Ménière's disease.

\section{Sudden Deafness}

A functional role of sympathetic projections from the SG in CBF regulation could be found in guinea pig [Laurikainen et al., 1993]. In addition, idiopathic sudden sensorineural hearing loss patients showed an altered autonomic regulation [Schulz et al., 2014]. A SG block based on the goal of improving internal ear circulatory disturbance appears to be beneficial for the treatment of sudden hearing loss [Takinami, 2012]. Therefore, oxygen inhalation with drug therapy and SG block is a useful treatment for sudden hearing loss [Ii et al., 1991]. It is a safe and effective administration of SG catheter retention with interrupted ropivacaine block [Gao et al., 2015]. However, it is premature to claim that SGB treatment shows a significant efficacy, reevaluation with a larger number of patients is still warranted in the future.

\section{Noise-Induced Hearing Loss}

Extensive research has been conducted on the relationship between $\mathrm{CBF}$ and the effects of noise exposure on the cochlea [Hawkins, 1971; Hultcrantz et al., 1979; Axelsson et al., 1981; Thorne and Nuttall, 1987; Ryan et al., 1988]. Noise-induced vascular ischemia was demonstrated to lead to reduced auditory sensitivity [Quirk and Seidman, 1995]. Cochlear oxygenation is an efficient way to protect the cochlea from noise-induced damage. Angiotensin receptor antagonist application protects against noise-induced microcirculatory ischemia and auditory sensitivity [Kellerhals, 1972; Miller et al., 1983; Hatch et al., 1991; Goldwyn et al., 1998]. Furthermore, SG blockade im- 
proved auditory parameters in rats with normal CBF, suggesting that SG blockade is a potential treatment option for vascular pathologies of the cochlea [Firat et al., 2008].

The discussion on the roles of sympathetic modulation of the cochlea extends to the effects of sympathetic regulation of the cochlear and noise overstimulation. A strong correlation between noise intensity and vagal-sympathetic balance has been reported [Valenti et al., 2012]. Furthermore, a protective role, which becomes significant 1 week after noise overstimulation, has been observed in simultaneous sympathetic nervous system stimulation when the cochlea is overstimulated with the stimuli between 110 and 115 sound pressure level for $10 \mathrm{~min}$ [Wada et al., 1999]. Hildesheimer et al. [1991] verified the protective value of cervical sympathectomy in stressful sound exposure conditions which produced a temporary threshold shift (TTS). Horner et al. [2001] used an animal model involving unilateral ablation of the superior cervical ganglion and observed a bilateral protective effect that suggested an intimate relationship between the sympathetic and olivocochlear efferent systems; this highlights new pathways underpinning protective mechanisms against TTS in the cochlea. Giraudet et al. [2002] proposed that protection from TTS under sedation/anesthesia may be due to diminished sympathetic influence. Additionally, a protective role of sympathectomy at different sound exposure levels resulted in a permanent threshold shift [Hildesheimer et al., 2002].

Sympathetic fibers modulate susceptibility to acoustic exposure, but the effects remain controversial [Bielefeld and Henderson, 2007]. Indeed, contradictory results have been reported [Maison et al., 2010]. In a $\mathrm{Dbh}^{-1-}$ mice model, mutant mice lacking measurable adrenaline or NE were more susceptible than controls to noise exposure. Activity in autonomic motor pathways is regulated by various sensory inputs, including auditory stimuli [Gibbins, 2013]. "Wideband" theta frequency binaural beats postexercise increased sympathetic withdrawal [McConnell et al., 2014]. The response of sympathetic nerves to task demands is mediated by the threat of social assessment, as reported in preliminary studies. However, in a listening task, the relative effects of motivation and emotional stress on physiological responses need to be further studied [Mackersie and Kearney, 2017]. NE in the inner ear is a potential biomarker for acute noise stress in the hippocampus [Jin et al., 2017]. Compared to individuals who did not feel excessive reactions, those who frequently felt excessive reactions to auditory stimuli tended to have excessive sympathetic responses to repeated extensive noises [Kato et al., 2014].

\section{Conclusion}

This review article summarizes the recent progress in regulation of the sympathetic nervous system on auditory function. In the peripheral auditory system, the sympathetic nervous system regulates $\mathrm{CBF}$, modulates cochlear efferent fibers, affects hair cells, and influences the habenula region. ARs modulate $\mathrm{CBF}$, and their distribution and function in the cochlea vary. In central auditory pathways, NE is essential for plasticity in the auditory cortex and affects auditory cortex activity. In pathological states, the sympathetic nervous system is associated with noiseinduced hearing loss by regulating $\mathrm{CBF}$. ARs may also regulate inner ear fluid ions in several diseases, such as vertigo. Several limitations in the literature exist. The distribution of sympathetic fiber terminals in hair cell regions remains clear, and their regulation of sensory cells has not been demonstrated. The mechanisms and pathways of sympathetic nervous system modulation of auditory function both peripherally and centrally have not been fully defined. The neurobiology of auditory circuit modulation is an area worthy of investigation.

\section{Conflict of Interest Statement}

The authors have no conflicts of interest to declare.

\section{Funding Sources}

This study was supported by the National Natural Science Foundation of China (NSFC 81870732), the Natural Science Foundation of Shaanxi (2018PT-01), and the Research Promotion Project from Xijing Hospital (XJZT14X07; XJZT15D02; XJZT18MDT07; XJZT18X23; and XJZT18D16).

\section{Author Contributions}

Chaoyong Tian drafted the first version of the manuscript. Chaoyong Tian and Dingjun Zha conceived, designed, and wrote jointly the final version of the manuscript. Both authors approved the final version of the manuscript.

References

Audiol Neurotol 2022;27:93-103 DOI: $10.1159 / 000517452$
Andén N-E, Fuxe K, Larsson K. Effect of large mesencephalic-diencephalic lesions on the noradrenalin, dopamine and 5-hydroxytryptamine neurons of the central nervous system. Experientia. 1966 Dec 15;22(12):842-3.

Axelsson A, Vertes D, Miller J. Immediate noise effects on cochlear vasculature in the Guinea pig. Acta Otolaryngol. 1981 Mar-Apr;91(34):237-46. 
Behrens EG, Schofield BR, Thompson AM. Aminergic projections to cochlear nucleus via descending auditory pathways. Brain Res. 2002 Nov 15;955(1-2):34-44.

Berridge CW, Waterhouse BD. The locus coeruleus-noradrenergic system: modulation of behavioral state and state-dependent cognitive processes. Brain Res Brain Res Rev. 2003 Apr; 42(1):33-84.

Beyerl BD. Afferent projections to the central nucleus of the inferior colliculus in the rat. Brain Res. 1978 Apr 28;145(2):209-23.

Biaggioni I, Costa F, Kaufmann H. Vestibular influences on autonomic cardiovascular control in humans. J Vestib Res. 1998 Jan-Feb;8(1): $35-41$.

Bielefeld EC, Henderson D. Influence of sympathetic fibers on noise-induced hearing loss in the chinchilla. Hear Res. 2007 Jan;223(1-2): $11-9$.

Borg E, Densert O, Flock A. Synaptic vesicles in the cochlea. Acta Otolaryngol. 1974 NovDec;78(5-6):321-32.

Boyajian CL, Loughlin SE, Leslie FM. Anatomical evidence for alpha-2 adrenoceptor heterogeneity: differential autoradiographic distributions of $[3 \mathrm{H}]$ rauwolscine and $[3 \mathrm{H}]$ idazoxan in rat brain. J Pharmacol Exp Ther. 1987 Jun; 241(3):1079-91.

Brechtelsbauer PB, Prazma J, Garrett CG, Carrasco VN, Pillsbury HC. Student Research Award 1990. Catecholaminergic innervation of the inner ear. Otolaryngol Head Neck Surg. 1990 Oct;103(4):566-74.

Burwood GWS, Dziennis S, Wilson T, Foster S, Zhang Y, Liu G, et al. The mechanoelectrical transducer channel is not required for regulation of cochlear blood flow during loud sound exposure in mice. Sci Rep. 2020 Jun 8;10(1): 9229.

Cai J, Li J, Liu W, Han Y, Wang H. a2-adrenergic receptors in spiral ganglion neurons may mediate protective effects of brimonidine and yohimbine against glutamate and hydrogen peroxide toxicity. Neuroscience. 2013a Jan 3; 228:23-35.

Cai J, Li J, Mao Y, Bai X, Xu L, Wang H. Immunohistochemical localization of $\alpha 2$-adrenergic receptors in the neonatal rat cochlea and the vestibular labyrinth. J Mol Neurosci. 2013b Nov;51(3):1010-20.

Carrasco VN, Prazma J, Faber JE, Triana RJ, Pillsbury HC. Cochlear microcirculation: effect of adrenergic agonists on arteriole diameter. Arch Otolaryngol Head Neck Surg. 1990 Apr; 116(4):411-7.

Chikamori Y, Sasa M, Fujimoto S, Takaori S, Matsuoka I. Locus coeruleus-induced inhibition of dorsal cochlear nucleus neurons in comparison with lateral vestibular nucleus neurons. Brain Res. 1980 Jul 21;194(1):53-63.

Coleman JR, Clerici WJ. Sources of projections to subdivisions of the inferior colliculus in the rat. J Comp Neurol. 1987 Aug 8;262(2):215-26.

Comis SD, Whitfield IC. Influence of centrifugal pathways on unit activity in the cochlear nucleus. J Neurophysiol. 1968 Jan;31(1):62-8.
Cortada M, Levano S, Bodmer D. Brimonidine protects auditory hair cells from in vitro-induced toxicity of gentamicin. Audiol Neurootol. 2017;22(3):125-34.

Dahlström A, Fuxe K. Localization of monoamines in the lower brain stem. Experientia. 1964 Jul 15;20(7):398-9.

Day HEW, Campeau S, Watson SJ, Akil H. Distribution of $a(1 \mathrm{a})-, \quad \alpha(1 \mathrm{~b})-$ and $\alpha(1 \mathrm{~d})$ adrenergic receptor mRNA in the rat brain and spinal cord. J Chem Neuroanat. 1997 Jul; 13(2):115-39.

de Minteguiaga C, Clerget MS, Tran Ba Huy P, Elalouf JM. beta2-adrenergic but not vasopressin V2 receptor mRNAs are expressed in the stria vascularis of the rat inner ear. Pflugers Arch. 1998 Nov;436(6):940-7.

Densert O. Adrenergic innervation in the rabbit cochlea. Acta Otolaryngol. 1974 Nov-Dec; 78(5-6):345-56.

Densert O, Flock A. An electron-microscopic study of adrenergic innervation in the cochlea. Acta Otolaryngol. 1974 Mar;77(3): 185-97.

Domyancic AV, Morilak DA. Distribution of $\alpha(1 a)$ adrenergic receptor mRNA in the rat brain visualized by in situ hybridization. J Comp Neurol. 1997 Sep 29;386(3):358-78.

Ebert U. Noradrenalin enhances the activity of cochlear nucleus neurons in the rat. Eur J Neurosci. 1996 Jun;8(6):1306-14.

Edeline JM, Manunta Y, Hennevin E. Induction of selective plasticity in the frequency tuning of auditory cortex and auditory thalamus neurons by locus coeruleus stimulation. Hear Res. 2011 Apr;274(1-2):75-84.

Fauser C, Schimanski S, Wangemann P. Localization of betal-adrenergic receptors in the cochlea and the vestibular labyrinth. J Membr Biol. 2004 Sep 1;201(1):25-32.

Firat Y, Kizilay A, Ozturan O, Ekici N. Experimental otoacoustic emission and auditory brainstem response changes by stellate ganglion blockage in rat. Am J Otolaryngol. 2008 Sep-Oct;29(5):339-45.

Foote SL, Freedman R, Oliver AP. Effects of putative neurotransmitters on neuronal activity in monkey auditory cortex. Brain Res. $1975 \mathrm{Mar}$ 21;86(2):229-42.

Franz B, Anderson CR. The effect of the sympathetic and sensory nervous system on active eustachian tube function in the rat. Acta Otolaryngol. 2007 Mar;127(3):265-72.

Friauf E, Ostwald J. Divergent projections of physiologically characterized rat ventral cochlear nucleus neurons as shown by intra-axonal injection of horseradish peroxidase. Exp Brain Res. 1988;73(2):263-84.

Gao H, Zhang Z, Guo W, Zhang G. [Stellate ganglion catheter retention with discontinuous block on efficacy and safety in the treatment of sudden deafness]. Lin Chung Er Bi Yan Hou Tou Jing Wai Ke Za Zhi. 2015 Jul;29(14): 1291-4.

Gibbins I. Functional organization of autonomic neural pathways. Organogenesis. 2013 JulSep;9(3):169-75.
Giraudet F, Horner KC, Cazals Y. Similar halfoctave TTS protection of the cochlea by xylazine/ketamine or sympathectomy. Hear Res. 2002 Dec;174(1-2):239-48.

Gjedde A, Dyve S, Yang YJ, McHugh M, Pappius HM. Bi-affinity alpha 1-adrenoceptor binding in normal rat brain in vivo. Synapse. 1991 Sep;9(1):1-6.

Goldwyn B, Khan MJ, Shivapuja BG, Seidman MD, Quirk WS. Sarthran preserves cochlear microcirculation and reduces temporary threshold shifts after noise exposure. Otolaryngol Head Neck Surg. 1998 May;118(5): 576-83.

Gruber DD, Dang H, Shimozono M, Scofield MA, Wangemann P. a(1A)-Adrenergic receptors mediate vasoconstriction of the isolated spiral modiolar artery in vitro. Hear Res. 1998 May; 119(1-2):113-24.

Grzanna R, Molliver ME. The locus coeruleus in the rat: an immunohistochemical delineation. Neuroscience. 1980;5(1):21-40.

Harrison JM, Feldman ML. Anatomical aspects of the cochlear nucleus and superior olivary complex. Contrib Sens Physiol. 1970;4:95-142.

Hatch M, Tsai M, LaRouere MJ, Nuttall AL, Miller JM. The effects of carbogen, carbon dioxide, and oxygen on noise-induced hearing loss. Hear Res. 1991 Nov;56(1-2):265-72.

Hawkins JE. The role of vasoconstriction in noiseinduced hearing loss. Ann Otol Rhinol Laryngol. 1971 Dec;80(6):903-13.

Hildesheimer M, Henkin Y, Pye A, Heled S, Sahartov E, Shabtai EL, et al. Bilateral superior cervical sympathectomy and noise-induced, permanent threshold shift in guinea pigs. Hear Res. 2002 Jan;163(1-2):46-52.

Hildesheimer M, Sharon R, Muchnik C, Sahartov E, Rubinstein M. The effect of bilateral sympathectomy on noise induced temporary threshold shift. Hear Res. 1991 Jan;51(1):49-53.

Hirao K, Eto K, Nakahata Y, Ishibashi H, Nagai T, Nabekura J. Noradrenergic refinement of glutamatergic neuronal circuits in the lateral superior olivary nucleus before hearing onset. J Neurophysiol. 2015 Sep;114(3):1974-86.

Horner KC, Giraudet F, Lucciano M, Cazals Y. Sympathectomy improves the ear's resistance to acoustic trauma: could stress render the ear more sensitive? Eur J Neurosci. 2001 Jan; 13(2):405-8.

Hozawa K, Kimura RS. Cholinergic and noradrenergic nervous systems in the cynomolgus monkey cochlea. Acta Otolaryngol. 1990 JulAug;110(1-2):46-55.

Hultcrantz E, Angelborg C, Beausang-Linder M. Noise and cochlear blood flow. Arch Otorhinolaryngol. 1979;224(1-2):103-6.

Hultcrantz E, Nuttall AL, Brown MC, Lawrence $M$. The effect of cervical sympathectomy on cochlear electrophysiology. Acta Otolaryngol. 1982 Nov-Dec;94(5-6):439-44.

Ii C, Miyazaki H, Tashiro M, Kakiuchi Y, Tsuno $\mathrm{K}, \mathrm{Habu} \mathrm{K}$, et al. [The effect of drug therapy and stellate ganglion block with or without oxygen inhalation on sudden hearing loss]. Masui. 1991 Aug;40(8):1251-5. 
Ikeda MZ, Jeon SD, Cowell RA, Remage-Healey L. Norepinephrine modulates coding of complex vocalizations in the songbird auditory cortex independent of local neuroestrogen synthesis. J Neurosci. 2015 Jun 24;35(25):9356-68.

Inamoto R, Miyashita T, Matsubara A, Hoshikawa $\mathrm{H}$, Mori $\mathrm{N}$. The difference in endolymphatic hydrostatic pressure elevation induced by isoproterenol between the ampulla and the cochlea. Auris Nasus Larynx. 2017 Jun;44(3): 282-7.

Ishii K, Zhai WG, Akita M. Effect of a beta-stimulant on the inner ear stria vascularis. Ann Otol Rhinol Laryngol. 2000 Jul;109(7):628-33.

Jang CH, Cho YB, Lee JS, Kim GH, Jung WK, Pak SC. The effect of propofol infusion with topical epinephrine on cochlear blood flow and hearing: an experimental study. Int J Pediatr Otorhinolaryngol. 2016 Dec;91:23-6.

Jin SG, Kim MJ, Park SY, Park SN. Stress hormonal changes in the brain and plasma after acute noise exposure in mice. Auris Nasus Larynx. 2017 Jun;44(3):272-6.

Jones BE, Halaris AE, Mcllhany M, Moore RY. Ascending projections of the locus coeruleus in the rat. I. axonal transport in central noradrenaline neurons. Brain Research. 1977 May 20;127(1):1-21.

Kato F, Iwanaga R, Chono M, Fujihara S, Tokunaga A, Murata J, et al. Relationship between sympathetic skin responses and auditory hypersensitivity to different auditory stimuli. J Phys Ther Sci. 2014 Jul;26(7):1087-91.

Kawasaki Y. Autonomic nervous function of vertiginous patients: assesment by spectral analysis of heart rate variability. Nihon Jibiinkoka Gakkai Kaiho. 1993 Mar;96(3):444-56.

Kellerhals B. Acoustic trauma and cochlear microcirculation. An experimental and clinical study on pathogenesis and treatment of inner ear lesions after acute noise exposure. Adv Otorhinolaryngol. 1972;18:91-168.

Kelly JB, Liscum A, Van Adel B, Ito M. Projections from the superior olive and lateral lemniscus to tonotopic regions of the rat's inferior colliculus. Hear Res. 1998 Feb;116(1-2): 43-54.

Khan KM, Drescher MJ, Hatfield JS, Ramakrishnan NA, Drescher DG. Immunohistochemical localization of adrenergic receptors in the rat organ of corti and spiral ganglion. J Neurosci Res. 2007 Oct;85(13):3000-12.

Kim BG, Kim JY, Jung J, Moon IS, Yoon JH, Choi JY, et al. $\beta 1$ - and $\beta 2$-adrenergic stimulationinduced electrogenic transport by human endolymphatic sac epithelium and its clinical implications. Sci Rep. 2017 Feb 6;7:42217.

Klepper A, Herbert H. Distribution and origin of noradrenergic and serotonergic fibers in the cochlear nucleus and inferior colliculus of the rat. Brain Res. 1991 Aug 23;557(1-2):190201.

Koning HM, Dyrbye BA, van Hemert FJ. Percutaneous radiofrequency lesion of the superior cervical sympathetic ganglion in patients with tinnitus. Pain Pract. 2016 Nov;16(8):9941000.
Kossl M, Vater M. Noradrenaline enhances temporal auditory contrast and neuronal timing precision in the cochlear nucleus of the mustached bat. J Neurosci. 1989 Dec;9(12):416978.

Lamm K, Arnold W. Noise-induced cochlear hypoxia is intensity dependent, correlates with hearing loss and precedes reduction of cochlear blood flow. Audiol Neurootol. 1996 May-Jun;1(3):148-60.

Laurikainen EA, Costa O, Miller JM, Nuttall AL, Ren TY, Masta R, et al. Neuronal regulation of cochlear blood flow in the guinea-pig. J Physiol. 1994 Nov 1;480(Pt 3):563-73.

Laurikainen EA, Kim D, Didier A, Ren T, Miller JM, Quirk WS, et al. Stellate ganglion drives sympathetic regulation of cochlear blood flow. Hear Res. 1993 Jan;64(2):199-204.

Laurikainen EA, Ren T, Miller JM, Nuttall AL, Quirk WS. The tonic sympathetic input to the cochlear vasculature in guinea pig. Hear Res. 1997 Mar; 105(1-2):141-5.

Lee AH, Møller AR. Effects of sympathetic stimulation on the round window compound action potential in the rat. Hearing Research. 1985;19(2):127-34.

Loughlin SE, Foote SL, Bloom FE. Efferent projections of nucleus locus coeruleus: Topographic organization of cells of origin demonstrated by three-dimensional reconstruction. Neuroscience. 1986 Jun;18(2):291-306.

Mackersie CL, Kearney L. Autonomic nervous system responses to hearing-related demand and evaluative threat. Am J Audiol. 2017 Oct 12;26(3S):373-7.

Maison SF, Le M, Larsen E, Lee SK, Rosowski JJ, Thomas SA, et al. Mice lacking adrenergic signaling have normal cochlear responses and normal resistance to acoustic Injury but enhanced susceptibility to middle-ear infection. J Assoc Res Otolaryngol. 2010 Sep;11(3):44961.

Manunta Y, Edeline JM. Effects of noradrenaline on frequency tuning of rat auditory cortex neurons. Eur J Neurosci. 1997 Apr;9(4):83347.

Manunta Y, Edeline JM. Effects of noradrenaline on frequency tuning of auditory cortex neurons during wakefulness and slow-wave sleep. Eur J Neurosci. 1999 Jun;11(6):213450.

Manunta Y, Edeline JM. Noradrenergic induction of selective plasticity in the frequency tuning of auditory cortex neurons. J Neurophysiol. 2004 Sep;92(3):1445-63.

Martin F, Marianowski R, Tu TY, Herman P, Tran Ba Huy P. Modulation of cyclic AMP production by strial marginal cells from gerbil in culture. Hear Res. 1994 Dec;81(1-2):3341.

Martins AR, Froemke RC. Coordinated forms of noradrenergic plasticity in the locus coeruleus and primary auditory cortex. Nat Neurosci. 2015 Oct;18(10):1483-92.

McBride RL, Sutin J. Noradrenergic hyperinnervation of the trigeminal sensory nuclei. Brain Res. 1984 Dec 24;324(2):211-21.
McConnell PA, Froeliger B, Garland EL, Ives JC, Sforzo GA. Auditory driving of the autonomic nervous system: listening to theta-frequency binaural beats post-exercise increases parasympathetic activation and sympathetic withdrawal. Front Psychol. 2014 Nov 14;5:1248.

Miller JM, Marks NJ, Goodwin PC. Laser doppler measurements of cochlear blood flow. Hear Res. 1983 Sep;11(3):385-94.

Mom T, Bonfils P, Gilain L, Avan P. Origin of cubic difference tones generated by high-intensity stimuli: effect of ischemia and auditory fatigue on the gerbil cochlea. J Acoust Soc Am. 2001 Sep;110(3 Pt 1):1477-88.

Moore RY, Bloom FE. Central catecholamine neuron systems: anatomy and physiology of the norepinephrine and epinephrine systems. Annu Rev Neurosci. 1979;2:113-68.

Muchnik C, Hildesheimer M, Nebel L, Rubinstein $\mathrm{M}$. Influence of catecholamines on cochlear action potentials. Arch Otolaryngol. 1983 Aug; 109(8):530-2.

Mulders WH, Robertson D. Morphological relationships of peptidergic and noradrenergic nerve terminals to olivocochlear neurones in the rat. Hear Res. 2000 Jun;144(1-2):53-64.

Mulders WH, Robertson D. Origin of the noradrenergic innervation of the superior olivary complex in the rat. J Chem Neuroanat. 2001 Jun;21(4):313-22.

Mulders WH, Robertson D. Noradrenergic modulation of brainstem nuclei alters cochlear neural output. Hear Res. 2005 Jun;204(1-2): 147-55.

Nagaraj BS, Linthicum FH. Autonomic innervation of the human middle ear: an immunohistochemical study. American Journal of Otolaryngology. 1998 Mar-Apr;19(2):75-82.

Nasehi M, Shahbazzadeh S, Ebrahimi-Ghiri M, Zarrindast MR. Bidirectional influence of amygdala $\beta 1$-adrenoceptors blockade on cannabinoid signaling in contextual and auditory fear memory. J Psychopharmacol. 2018 Aug; 32(8):932-42.

Nuttall AL. Sound-induced cochlear ischemia/ hypoxia as a mechanism of hearing loss. Noise Health. 1999;2(5):17-32.

Ohlsen KA, Baldwin DL, Nuttall AL, Miller JM. Influence of topically applied adrenergic agents on cochlear blood flow. Circ Res. 1991 Aug;69(2):509-18.

Oliver DL. Ascending efferent projections of the superior olivary complex. Microsc Res Tech. 2000 Nov 15;51(4):355-63.

Osen KK, Mugnaini E, Dahl AL, Christiansen AH. Histochemical localization of acetylcholinesterase in the cochlear and superior olivary nuclei. A reappraisal with emphasis on the cochlear granule cell system. Arch Ital Biol. 1984 Sep;122(3):169-212.

Papay R, Gaivin R, Jha A, McCune DF, McGrath JC, Rodrigo MC, et al. Localization of the mouse $\alpha 1 \mathrm{~A}$-adrenergic receptor $(\mathrm{AR})$ in the brain: $\alpha 1 \mathrm{AAR}$ is expressed in neurons, GABAergic interneurons, and NG2 oligodendrocyte progenitors. J Comp Neurol. 2006 Jul 10; 497(2):209-22. 
Passe ER. Surgery of the sympathetic for Ménière's disease, tinnitus, and nerve deafness. AMA Arch Otolaryngol. 1953 Mar;57(3): 257-66.

Pérez-Valenzuela C, Gárate-Pérez MF, Sotomayor-Zárate R, Delano PH, Dagnino-Subiabre A. Reboxetine improves auditory attention and increases norepinephrine levels in the auditory cortex of chronically stressed rats. Front. Neural Circuits. 2016 Dec 27;10:108.

Perlman HB, Kimura R, Fernandez C. Experiments on temporary obstruction of the internal auditory artery. Laryngoscope. 1959 Jun; 69(6):591-613.

Perlman HB, Kimura RS. Observations of the living blood vessels of the cochlea. Ann Otol Rhinol Laryngol. 1955 Dec;64(4):1176-92.

Pickles JO. An investigation of sympathetic effects on hearing. Acta Otolaryngol. 1979 JanFeb;87(1-2):69-71.

Quirk WS, Seidman MD. Cochlear vascular changes in response to loud noise. Am J Otol. 1995 May;16(3):322-5.

Ray CA, Carter JR. Vestibular activation of sympathetic nerve activity. Acta Physiol Scand. 2003 Mar;177(3):313-9.

Ray CA, Monahan KD. The vestibulosympathetic reflex in humans: neural interactions between cardiovascular reflexes. Clin Exp Pharmacol Physiol. 2002 Jan-Feb;29(1-2):98-102.

Ren T, Brown NJ, Zhang M, Nuttall AL, Miller JM. A reversible ischemia model in gerbil cochlea. Hear Res. 1995 Dec;92(1-2):30-7.

Ren T, Laurikainen E, Quirk WS, Miller JM, Nuttall AL. Effects of stellate ganglion stimulation on bilateral cochlear blood flow. Ann Otol Rhinol Laryngol. 1993a May;102(5):378-84.

Ren TY, Laurikainen E, Quirk WS, Miller JM, Nuttall AL. Effects of electrical stimulation of the superior cervical ganglion on cochlear blood flow in Guinea pig. Acta Otolaryngol. 1993b Mar;113(2):146-51.

Rico B, Cavada C. Adrenergic innervation of the monkey thalamus: an immunohistochemical study. Neuroscience. 1998 Jun;84(3):839-47.

Ryan AF, Axelsson A, Myers R, Woolf NK. Changes in cochlear blood flow during acoustic stimulation as determined by $14 \mathrm{c}$-iodoantipyrine autoradiography. Acta Otolaryngol. 1988 Mar-Apr;105(3-4):232-41.

Salgado H, García-Oscos F, Dinh L, Atzori M. Dynamic modulation of short-term synaptic plasticity in the auditory cortex: the role of norepinephrine. Hear Res. 2011 Jan;271(12):26-36.

Salgado H, Garcia-Oscos F, Martinolich L, Hall S, Restom R, Tseng KY, et al. Pre- and postsynaptic effects of norepinephrine on $\gamma$-aminobutyric acid-mediated synaptic transmission in layer $2 / 3$ of the rat auditory cortex. Synapse. 2012 Jan;66(1):20-8.

Santi PA, Duvall AJ. Stria vascularis pathology and recovery following noise exposure. Otolaryngology. 1978 Mar-Apr;86(2):ORL354-61.

Schicknick H, Henschke JU, Budinger E, Ohl FW, Gundelfinger ED, Tischmeyer W. $\beta$-adrenergic modulation of discrimination learning and memory in the auditory cortex. Eur J Neurosci. 2019 Oct;50(7):3141-63.

Schimanski S, Scofield MA, Wangemann P. Functional beta2-adrenergic receptors are present in nonstrial tissues of the lateral wall in the gerbil cochlea. Audiol Neurootol. 2001 May-Jun;6(3):124-31.

Schulz S, Ritter J, Oertel K, Witt K, Bär KJ, Guntinas-Lichius $\mathrm{O}$, et al. Altered autonomic regulation as a cardiovascular risk marker for patients with sudden sensorineural hearing loss. Otol Neurotol. 2014 Dec;35(10):1720-9.

Seymour JC, Tappin JW. The effect of sympathetic stimulation upon the cochlear microphonic potentials. J Laryngol Otol. 1951 Dec; 65(12):851-8

Shepard KN, Liles LC, Weinshenker D, Liu RC. Norepinephrine is necessary for experiencedependent plasticity in the developing mouse auditory cortex. J Neurosci. 2015 Feb 11; 35(6):2432-7.

Shi X. Physiopathology of the cochlear microcirculation. Hear Res. 2011 Dec;282(1-2):10-24.

Shimizu M, Matsuzuka T, Matsumi F, Ogawa H, Murono S. Change of tinnitus with xenon phototherapy of the stellate ganglion. Photomed Laser Surg. 2018 Sep;36(9):468-71.

Spoendlin H. Autonomic innervation of the inner ear. Adv Otorhinolaryngol. 1981;27:1-13.

Spoendlin $\mathrm{H}$, Lichtensteiger $\mathrm{W}$. The adrenergic innervation of the labyrinth. Acta Otolaryngol. 1966 May;61(5):423-34.

Spoendlin H, Lichtensteiger W. The sympathetic nerve supply to the inner ear. Arch Klin Exp Ohren Nasen Kehlkopfheilkd. 1967;189(4): 346-59.

Sutin J, Minneman KP. alpha 1- and beta-adrenergic receptors are co-regulated during both noradrenergic denervation and hyperinnervation. Neuroscience. 1985 Apr;14(4):973-80.

Takinami Y. Evaluation of effectiveness of stellate ganglion block (SGB) treatment of sudden hearing loss. Acta Otolaryngol. 2012 Jan; 132(1):33-8.

Thalmann R, Miyoshi T, Thalmann I. The influence of ischemia upon the energy reserves of inner ear tissues. Laryngoscope. 1972 Dec; 82(12):2249-72.

Thompson AM, Thompson GC. Relationship of descending inferior colliculus projections to olivocochlear neurons. J Comp Neurol. 1993 Sep 15;335(3):402-12.

Thorne PR, Nuttall AL. Laser doppler measurements of cochlear blood flow during loud sound exposure in the guinea pig. Hear Res. 1987;27(1):1-10.

Uddman R, Kitajiri M, Sundler F. Autonomic innervation of the middle ear. Ann Otol Rhinol Laryngol. 1983 Mar-Apr;92(2 Pt 1):151-4.

Valenti V, Guida H, Frizzo A, Cardoso A, Vanderlei L, Abreu L. Auditory stimulation and cardiac autonomic regulation. Clinics. 2012 Aug; 67(8):955-8.

Vicente-Torres MA, Gil-Loyzaga P. Age- and gender-related changes in the cochlear sympathetic system of the rat. Neurosci Lett. 2002 Feb 22;319(3):177-9.
Wada T, Takahashi K, Ito Z, Hara A, Takahashi H, Kasakari J. The protective effect of the sympathetic nervous system against acoustic trauma. Auris Nasus Larynx. 1999 Oct;26(4):375-82.

Wanaka A, Kiyama H, Murakami T, Matsumoto M, Kamada T, Malbon CC, et al. Immunocytochemical localization of beta-adrenergic receptors in the rat brain. Brain Res. 1989 Apr 17;485(1):125-40.

Wangemann P, Wonneberger K. Neurogenic regulation of cochlear blood flow occurs along the basilar artery, the anterior inferior cerebellar artery and at branch points of the spiral modiolar artery. Hear Res. 2005 Nov;209(12):91-6.

Warrick JW. Stellate ganglion block in the treatment of Ménière's disease and in the symptomatic relief of tinnitus. Br J Anaesth. 1969 Aug;41(8):699-702.

Williams CA, Miller KE, Williams NP, Portfors CV, Perkel DJ. Distribution and co-expression of adrenergic receptor-encoding mRNA in the mouse inferior colliculus. J Comp Neurol. 2021 Jun;529(8):1743-55.

Winzer-Serhan UH, Leslie FM. Expression of $a(2 a)$ adrenoceptors during rat neocortical development. J Neurobiol. 1999 Feb 5;38(2): 259-69.

Woods CI, Azeredo WJ. Noradrenergic and serotonergic projections to the superior olive: potential for modulation of olivocochlear neurons. Brain Res. 1999 Jul 31;836(1-2):9-18.

Wynne B, Robertson D. Localization of dopamine-beta-hydroxylase-like immunoreactivity in the superior olivary complex of the rat. Audiol Neurootol. 1996 Jan-Feb;1(1):54-64.

Yates BJ. Vestibular influences on the sympathetic nervous system. Brain Res Brain Res Rev. 1992 Jan-Apr;17(1):51-9.

Yates BJ, Billig I, Cotter LA, Mori RL, Card JP. Role of the vestibular system in regulating respiratory muscle activity during movement. Clin Exp Pharmacol Physiol. 2002 Jan-Feb; 29(1-2):112-7.

Yates BJ, Holmes MJ, Jian BJ. Adaptive plasticity in vestibular influences on cardiovascular control. Brain Res Bull. 2000 Sep 1;53(1):3-9.

Yates BJ, Kerman IA. Post-spaceflight orthostatic intolerance: possible relationship to microgravity-induced plasticity in the vestibular system. Brain Res Brain Res Rev. 1998 Nov; 28(1-2):73-82.

Yildiz SK, Koybasi S, Turkoglu SA, Yildiz N, Korkmaz B, Akyurek F. Sympathetic skin responses from postauricular region in $\mathrm{Me}$ niere's disease. Clin Neurophysiol. 2007 Sep; 118(9):1991-8.

Ylikoski J, Lehtimäki J, Pirvola U, Mäkitie A, Aarnisalo A, Hyvärinen P, et al. Non-invasive vagus nerve stimulation reduces sympathetic preponderance in patients with tinnitus. Acta Otolaryngol. 2017 Apr;137(4):426-31.

Zha DJ, Wang ZM, Lin Y, Liu T, Qiao L, Lu LJ, et al. Effects of noradrenaline on the GABA response in rat isolated spiral ganglion neurons in culture. J Neurochem. 2007 Oct;103(1):5766. 